\title{
Analytical friction force compensation of flow curves out of layer compression tests with the pin extrusion test
}

\author{
Matthias Lenzen $^{1}$ - Martin Kraus ${ }^{1}$ - Marion Merklein ${ }^{1}$ \\ Received: 20 August 2019 / Accepted: 25 March 2020 / Published online: 29 April 2020 \\ (C) The Author(s) 2020
}

\begin{abstract}
For conventional material models like Yld2000-2d or BBC05 the equi-biaxial yield strength is required for the parameter identification. In this context, a commonly used test setup is the hydraulic bulge test. However, an inaccuracy in the characterization of the initial yield strength is present in the hydraulic bulge test. Due to the evaluation of the resulting curvature of the specimen, that is nearly infinite at the onset of yielding, the calculated stress can significant vary. Another proposed test setup for the characterization of the equi-biaxial stress state is the layer compression test. Here, the onset of yielding can be characterized with sufficient accuracy. The disadvantage in this test is the friction between stack and tool that leads to an overestimation of the flow curve. Thus, robust and experimental based friction compensation should be used, to gain a comparable hardening behaviour as in the hydraulic bulge test. In this contribution, the friction in the layer compression test is compensated by characterization of the tribological conditions. Thus, the tribological system consisting of workpiece surface, tool surface and lubricant is characterized using pin extrusion tests. The friction is analysed for the two steel grades DC06 and DP600 and the aluminium AA5182. With the identified friction factors, the measured testing force in the layer compression test is reduced by the portion of friction. For verification, hydraulic bulge tests, which are approximately friction free, are performed and compared with the resulting flow curves of the layer compression tests. Results confirm, that a friction compensation of the layer compression tests lead to a significant improvement of the resulting material parameters in comparison to the hydraulic bulge tests. Additional, a new method for the friction factor characterization is presented that uses in the stress difference of flow curves characterized in hydraulic bulge tests and layer compression tests.
\end{abstract}

Keywords Layer compression test $\cdot$ Pin extrusion test $\cdot$ Friction compensation $\cdot$ Material characterization

\begin{tabular}{ll}
\multicolumn{2}{l}{ Nomenclature } \\
$\gamma_{\text {shear }}$ & Shear strain \\
$\varepsilon$ & Testing velocity \\
$\varepsilon_{\mathrm{eq}}$ & True equivalent strain \\
$\varepsilon_{\mathrm{x}}$ & Strain in $\mathrm{x}$ direction \\
$\varepsilon_{\mathrm{y}}$ & Strain in y direction \\
$\sigma$ & Flow stress \\
$\sigma_{\mathrm{HS}}$ &
\end{tabular}

Matthias Lenzen

matthias.lenzen@fau.de

Martin Kraus

martin.kraus@fau.de

Marion Merklein

marion.merklein@fau.de

1 Institute of Manufacturing Technology,

Friedrich-Alexander-Universität Erlangen-Nürnberg, Egerlandstr.

11-13 91058, Erlangen, Germany
Plastic flow stress calculated with the Hockett-

Sherby model

$\sigma_{\mathrm{m}} \quad$ Von Mises stress

$\tau_{\mathrm{F}} \quad$ Friction shear stress

$\tau_{\text {shear }} \quad$ Shear stress

A Cross section area

$\mathrm{d}_{\mathrm{d}} \quad$ Pin diameter

$\mathrm{d}_{\text {die }} \quad$ Diameter of die in the hydraulic bulge test

e Euler's number

$\mathrm{F}_{\text {friction }} \quad$ Friction force

$\mathrm{F}_{\text {layer }} \quad$ Force in the layer compression specimen

compression

$\mathrm{F}_{\mathrm{P}} \quad$ Punch force

$F_{\text {testing }} \quad$ Force measured in tests

h Specimen/ Pin height

k Shear flow stress

$\mathrm{k}_{\text {shear }} \quad$ Shear flow stress calculated with shear test data

$\mathrm{k}_{\text {tensile }} \quad$ Shear flow stress calculated with tensile test data

$\mathrm{m} \quad$ Friction factor 


$\begin{array}{ll}\mathrm{n} & \text { Testing iterations } \\ \mathrm{r}_{\mathrm{CB}} & \text { Radius of specimen in pin extrusion test } \\ \mathrm{r}_{\mathrm{DC}} & \text { Die radius in pin extrusion test } \\ \mathrm{R}_{\mathrm{a}} & \text { Mean roughness } \\ \mathrm{R}_{\mathrm{pk}} & \text { Reduced peak height } \\ \mathrm{R}_{\mathrm{z}} & \text { Mean roughness depth } \\ \mathrm{t} & \text { Sheet thickness } \\ \mathrm{HBT} & \text { Hydraulic bulge test } \\ \text { LCT } & \text { Layer compression test } \\ \mathrm{PET} & \text { Pin extrusion test } \\ \mathrm{RMSE} & \text { Root mean squared error } \\ \mathrm{SD} & \text { Standard deviation }\end{array}$

\section{Introduction}

Experimentally determined material parameters play a major role in the numerical simulation of manufacturing processes as an input for the parameter identification of the used material models. Over the years, several mathematical models have been developed that describe the flow behaviour of the material in the multiaxial stress space in a more or less complex way. Common models, that are used in the numerical simulation of deep drawing operations are Hill'90 [1], Barlat'91 [2], Yld2000-2d [3] or BBC05 [4]. All mentioned models need the flow behaviour under equi-biaxial loading. Thus, several test setups have been developed to identify this material parameter. The most common test setups are the layer compression test (LCT), the hydraulic bulge test (HBT) standardised in the ISO 16808:2014 [5] and the biaxial tensile test standardised in ISO 16842 [6]. The determination of material properties in the biaxial tensile test is challenging and the reachable maximum strain is low in comparison to other test setups. Due to the hydraulic fluid, the hydraulic bulge test is almost friction free. By using an 3D optical strain measurement device, as proposed by Güner et al. [7], the measurement of the pole height becomes obsolete. With the measured curvature, the evaluation of flow curves is done with formulations from shell theory using the pressure [8]. In this setup, the disadvantage is the mathematical stress formulation by using the radii. At the beginning of the test, the curvature radius is nearly infinite. This leads to a comparatively high standard deviation in contrast to higher degrees of deformation, where the curvature can be determined very accurate [8]. Panknin recommended a minimum true strain for the evaluation of 0.05 since there is a major influence of measuring errors and geometrical defects [8]. Following his recommendation, an identification of flow rules in the onset of yielding can lead to wrong results due to the high standard deviation below 0.05 true strain. In contrast to the hydraulic bulge test, the flow behaviour can be calculated over the complete deformation with a constantly low standard deviation in the layer compression test. Another advantage in the layer compression test is the very small specimen geometry. Challenging in this test is the presence of friction between stack and tool which can lead to a wrong calculation of the flow curve by using the measured testing force. An and Vegter [9] showed this gap in the flow curve between compression and bulge test. There, the plastic flow under bulging was on a higher level than in layer compression tests. This can be traced back to the used Erichsen deep drawing machine with a rigid punch for the bulge tests with a punch that has an even higher friction than the layer compression test and thus lead to wrong results when calculating flow curves. It has to be mentioned, that friction is just one influencing factor the work hardening. Vegter and An later proposed a correction function for the friction based on the von Mises friction in [10] and a correction with a friction-hill analysis in [11]. This improves the comparability between layer compression test and hydraulic bulge test but still leads to discrepancies of the flow stress in layer compression tests larger than 0.2 plastic strain. The used shear stress has been calculated with extruded aluminium cylinders and rings in [12]. Thus, the results can only give an approximate solution for the friction factor due to the usage of an extruded aluminium alloy for a general friction determination. Eder et al. [13] used a calibration function to compensate the friction in a Nakajima test and the calculated flow curves are comparable to the hydraulic bulge test. The first who compensated the friction in a layer compression test was Hochholdinger et al. [14]. They used inverse modelling methods to compensate the friction between stack and tool by comparing the resulting specimen geometry after compression with numerical results calculated with different values of the coulomb friction. This results in a value of 0.2 for the coulomb friction. However, the layer compression test should be seen as a bulk metal forming process, since the test setup is derived from the standard of compression test of a full cylinder. Alves et al. [15] have proven that a stack of similar material is comparable to a massive testing specimen with the same geometry. In the layer compression test, the testing forces are too high for the applicability of the coulomb friction law. Thus, the coulomb friction is not suitable in this case and the friction factor with a critical shear stress should be used [16].

For the determination of the friction factor, several test setups have been published. A common test is the barrel compression test, where a cylindrical specimen is deformed and the resulting curvature is used for the calculation of the friction factor [17]. By using the radius at the contact area between tool and specimen and the radius at the centre of the specimen the friction factor can be calculated. Another setup for the friction factor determination is the double cup extrusion test proposed by Schrader et al. [18]. Due to the higher reachable degree of deformation and the higher contact stress than in a compression test, this setup is more suitable for characterization of the tribological conditions in an extrusion process. These mentioned test setups can be used exclusively for bulk metal forming because of the specimen geometry. In the field 
of sheet bulk metal forming, ring compression tests and pin extrusion tests (PET) are used to determine the friction coefficients and friction factors [19]. The ring compression test from Male and Cockcroft [20] allows the identification of friction coefficients [21] as well as friction factors [22]. Within this test, the relationship between inner and outer diameter after compression is used to calculate a friction factor. According to Vierzigmann [19], the contact normal stresses in the pin extrusion test are above the validity limit of the Coulomb friction model of $3 \cdot \mathrm{k}_{\mathrm{f}}$. Thus, this test is mainly used for the determination of friction factors. The first to use an open-die backward extrusion test were Sofuoglu and Gedikli [23]. In this test setup, a punch with a cylindrical cavity is pressed on a circular specimen and in relation to the friction between tool and specimen the dominant material flow direction is towards the cavity or radial to the punch. This leads to a differing height of the extruded pin according to the present friction conditions.

In this contribution, the pin extrusion test is used for the characterization of the friction factor of sheet material and further to compensate the friction influence in the layer compression test. The difference of the flow curves in the layer compression test and the hydraulic bulge test should be relied on the friction since the layer compression test and the hydraulic bulge test are used for the characterization of the same stress state. The hydraulic bulge test results are not suitable for material modelling when using the flow stress at the onset of yielding, since the flow curve evaluation in hydraulic bulge tests is inaccurate below 0.05 true strain. Due to the equivalent use of both testing setups for flow curve characterization, it should be expected, that the resulting plastic material behaviour is identical. As the resulting material parameters of both tests vary, the friction should influence the flow curve calculation. Moreover, a compensation method for the elimination of the influence of friction on the flow curve is presented.

\section{Materials and experimental setups}

\section{Layer compression test}

To quantify the material properties under equi-biaxial stress, layer compression tests are performed. These tests are carried out on an universal testing machine (zmart.pro, Zwick AG, Germany) with a nominal force of $300 \mathrm{kN}$. The roughness value of the tools is $0.388 \mathrm{R}_{\mathrm{a}}$. The strain measurement is done with two 3D optical strain measurement devices (Aramis, GOM GmbH, Germany) which are mounted at an angle of $90^{\circ}$ to measure the deformation in rolling and transversal direction, see Fig. 1. For statistical purpose, three tests are performed for each material.

Each specimen contains 15 circular blanks with a diameter of $15 \mathrm{~mm}$. For specimen preparation, each blank is arranged on top of the other. According to standard for compression testing DIN 50106 [24], the ratio has to be one or higher. Thus, the resulting stack has a height to width ratio of one.

All plates are adjusted in rolling direction, to guarantee a homogeneous deformation of the entire stack. A white paint is applied on the stack as primer for the black stochastic pattern that is necessary for the optical strain measurement. After preparation, the specimen is centred on the lower tool. The orientation of the stack is adjusted that the first optical strain measurement system measures the deformation in rolling direction, while the second system is focused on the transversal direction. The strain measurement is done in the mid layer of the specimen. The friction between stack and tools is reduced by a sheet of PTFE foil with $0.05 \mathrm{~mm}$ thickness. The reduction of the friction is necessary, in order to minimize the bulging of the specimen between the upper and lower tool as known from the cylinder compression test. The PTFE sheet is applied under and above the specimen. The test is done with a constant deformation rate of $5 \mathrm{~mm} /$ min. This leads to strain rates, which are comparable to the strain rates resulting from uniaxial tensile tests and hydraulic bulge tests. The termination of the test is set to $50 \%$ height reduction. The evaluation of the stress based material characteristic is done according to the procedure proposed by Merklein and Kuppert [25]. The true stress $\sigma$ is calculated with the equation

$\sigma\left(\varepsilon_{e q}\right)=\frac{F_{\text {testing }}\left(\varepsilon_{e q}\right)}{A\left(\varepsilon_{e q}\right)}$

by using the testing Force $F_{\text {testing. }}$. With the optical DIC measurement, the height reduction of the specimen can be used for the calculation of the actual cross section area and the Euler's number e:

$A\left(\varepsilon_{e q}\right)=h_{0} \cdot e^{-\varepsilon_{e q}}$

The initial height $h_{0}$ of the specimen is calculated by the number of sheets and the initial sheet thickness $t_{0}$. The true equivalent strain $\varepsilon_{v}$ is calculated out of the two strain components $\varepsilon_{x}$ and $\varepsilon_{y}$ measured with the two optical DIC measurement systems using the von Mises equivalent strain formulation:

$\varepsilon_{e q}=\sqrt{\frac{2}{3}\left(\varepsilon_{x}{ }^{2}+\varepsilon_{y}{ }^{2}+\left(\varepsilon_{x}+\varepsilon_{y}\right)^{2}\right)}$

An elastic compensation of the true equivalent strain is done with a linear regression method according to [26]. 
Fig. 1 Setup for layer compression test with optical strain measurement

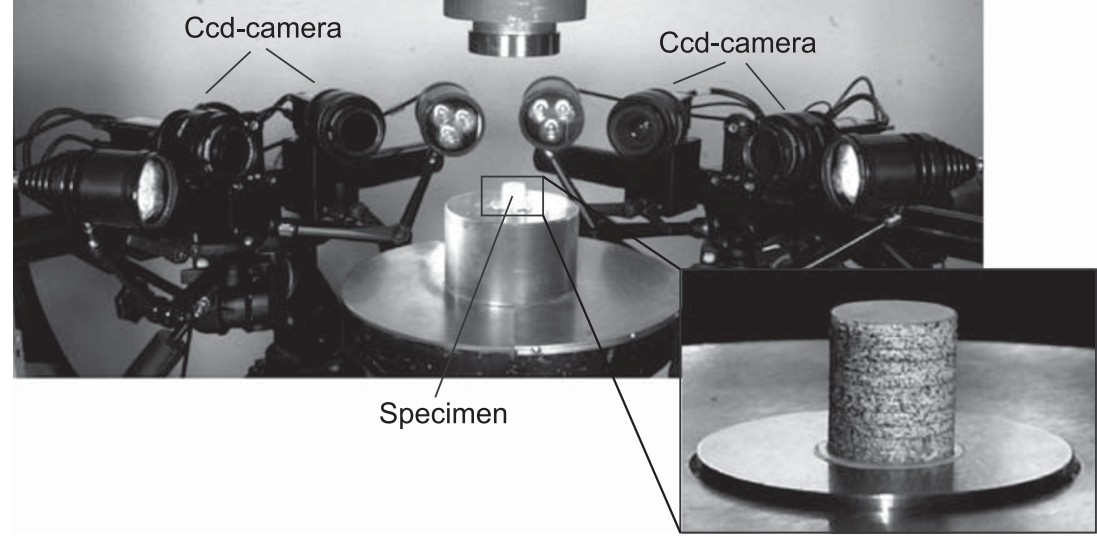

\section{Hydraulic bulge test}

For a comparison of the resulting flow curves in layer compression tests, hydraulic bulge tests are performed with the same materials. This test setup has the advantage, that there is no contact between tool and specimen in the evaluation zone. Thus, it can be seen as an almost friction free test. Due to the absence of friction, this material test is used for the verification of the proposed friction compensation that is presented later in this contribution. The tests are done by charging a specimen with a hydraulic fluid on the one side and measuring the resulting deformation with a 3D optical strain measurement device (Aramis, GOM GmbH, Germany) [27]. Testing and the evaluation of the material parameters are done according to the standard DIN EN ISO 16808 [5]. Due to the die diameter to sheet thickness portion of

$\frac{d_{\text {die }}}{t_{0}}=200$

the intrinsic bending of the sheet can be neglected in the strain evaluation [5]. For the stress calculation, the membrane theory is assumed. However, the stress evaluation is done according to the standardized procedure in DIN EN ISO 16808 [5]. Any effect of not balanced biaxial stress that has been investigated by Min et al. [28] is neglected.

\section{Pin extrusion test}

Due to the similar load spectrum and an identical specimen size as in the layer compression test, the mean friction factors for the materials DC06, DP600 and AA5182 are determined by pin extrusion test. This test is based on Burgdorf [29] and is suitable for the determination of friction coefficients and factors in sheetbulk-metal forming processes [19]. According to DIN 8582 [30], the pin extrusion test is a combination of extrusion and upsetting. The test setup and all relevant dimensions of the specimens and tools are shown in Fig. 2a. The pin extrusion test consists of a die with a hole of $1.0 \mathrm{~mm}$ and a flat die. The roughness value of the tools is $0.078 \mathrm{R}_{\mathrm{a}}$. To ensure a repeatable compression height, stoppers are used. The stopper thickness is selected depending on the material to achieve a compression of $50 \%$ of the initial sheet thickness according to the layer compression test which end at 50\% compression as well. Analogous to the layer compression test, PTFE foil is used to reduce the friction between specimen and tool. The experimental tests are carried out on a hydraulic forming machine (Lasco TSP 1000, LASCO Umformtechnik GmbH, Germany). During the test, the flat die moves downwards with a constant velocity of $2 \mathrm{~mm} / \mathrm{s}$ until the maximum press force of $720 \mathrm{kN}$ is reached. This results in an axial and radial material flow. The radial material flow in the sheet plane flows partly in the direction of the die cavity and mostly outwards. The superposition of the axial and radial material flow towards the cavity forms the pin. The tribological conditions between specimen and tool surface have a major influence on the achievable pin height. Due to the large contact surface and the high contact pressure the radial material flow is mainly influenced. By increasing the friction, the material flow towards the die cavity increases, since the dominant radial outward directed material flow is impeded. The die cavity is designed conical to improve the sensitivity of the test and to minimize the influence of the friction on the axial material flow. Due to the resulting smaller contact area at the pin surface, the influence of friction on the axial material flow can be neglected. After forming, the achieved pin heights are measured between the underside of the specimen and the pin top optically by confocal microscopy ( $\mu$ Surf, NanoFokus AG, Germany). Experimental pin extrusion tests can only evaluate the different tribological conditions qualitatively based on the varying pin heights. For a quantitative characterization of the tribological conditions a numerical model is required to determine friction factors. For this purpose, the pin heights of the experiments are compared to the resulting pin heights of numerical simulated pin extrusion tests with varying friction factors. The process is calculated numerically by using FEM-Software (simufact.forming.14.0, MSC 


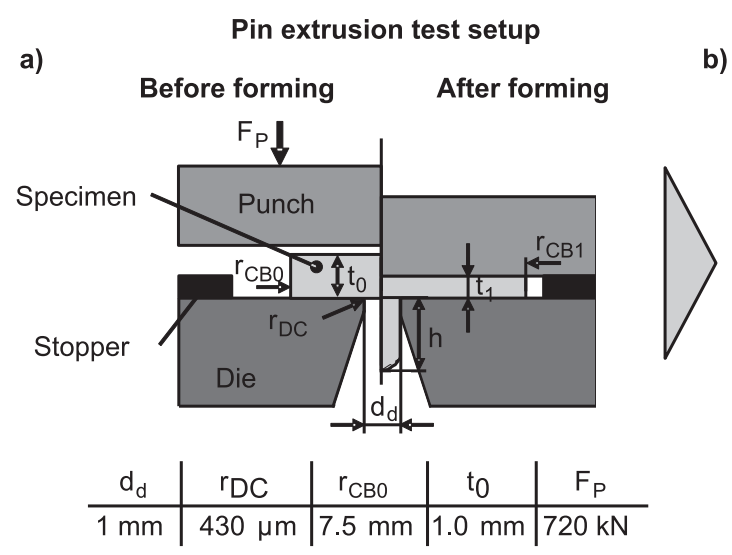

Fig. 2 a Pin extrusion test setup and $\mathbf{b}$ numerical identification

Software, USA). The numerical approach is needed for the comparison of the numerical pin heights with the experiments. For this purpose, a two-dimensional, rotationally symmetrical FE model is used, which has been validated in [31]. This model is calculated for all used materials for friction factors between $\mathrm{m}=$ 0.05 and $m=0.15$. Subsequently, the pin height is evaluated as a function of the friction factor for the residual sheet thickness $t_{1}$ in the experiments. A regression line which describes the relation between the pin height and the friction factor is generated from the numerical data points by using the best-fit method. Finally, the mean friction factors are identified by using the numerical determined calibration curves and the measured pin heights from the experiment (Fig. 2b). Any pressure dependency of the topological conditions and the resulting friction forces are averaged for this study.

\section{Materials}

The mild steel DC06, which is commonly used in cold forming operations, is used for the investigation. Characteristic for this alloy is the high ductility in combination with an excellent work hardening. Thus, it is used for complex parts in the automotive industry. Moreover, a second steel grade, DP600, is considered in this investigation. The high strength dual phase steel is mainly used in vibrating environments for example wheel rims. Investigations with aluminium are done by means of the alloy AA5182-O. This aluminium grade is used for body parts in the automotive industry. Due to the PLC effect [32], this material is not used for outer body parts.

The surface properties of the sheet material are measured by confocal microscopy ( $\mu$ Surf, NanoFokus AG, Germany). The topography is measured in a $4 \times 4 \mathrm{~mm}$ square with a $20 \times$ lens. The roughness values of the technical surface are determined with the measured surface topographies according to DIN EN ISO 4287 [33]. The roughness values are given in Table 1.

Further, the used flow curves of all three materials, characterized in uniaxial tensile tests in rolling direction, in shear tests and hydraulic bulge tests are shown in Fig. 3. For the

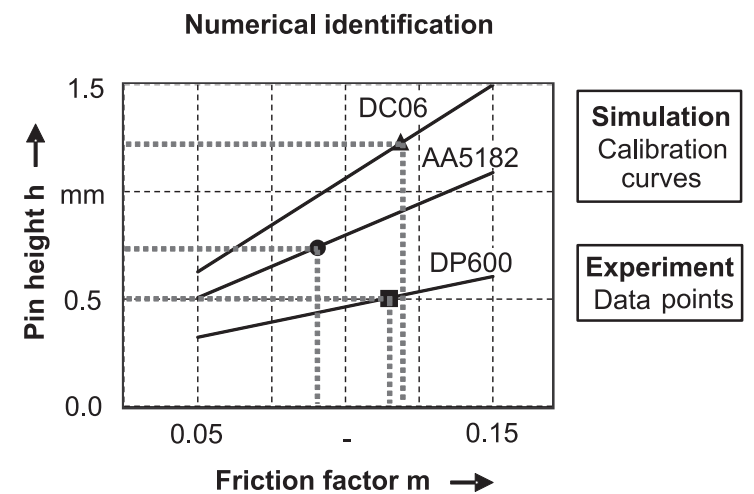

DC06 a strongly anisotropic hardening is visible, while for the AA5182-O and the DP600 no significant anisotropy in the hardening is observed. For each testing setup, three tests are carried out $(n=3)$.

\section{Quantification of the influence of the friction on the testing force}

For modelling the plastic material behaviour with data from layer compression tests, it has to be proven that the flow curves in layer compression tests are comparable to the results of hydraulic bulge tests. Especially the influence of the friction in the layer compression tests cannot be neglected and has to be evaluated and compensated. The friction can be seen as a flow restriction force in radial direction and has to be reduced from the measured testing force $\mathrm{F}_{\text {testing. }}$. The schematic influence of the friction in radial direction is depicted in Fig. 4.

The friction force $\mathrm{F}_{\text {friction }}$ reduces the force in the radial direction which is responsible for the deformation of the specimen. The resulting true testing force is defined as $\mathrm{F}_{\text {layer }}$ compression:

$F_{\text {layer compression }}=F_{\text {testing }}-F_{\text {friction }}$

The friction force $\mathrm{F}_{\text {friction }}$ can be calculated with the friction shear stress $\tau_{F}$ and the cross section area A:

$F_{\text {friction }}=\tau_{F} \cdot A$

By using the in pin extrusion tests evaluated friction factor $\mathrm{m}$ and the shear flow stress $\mathrm{k}$, the friction shear stress is calculated:

$\tau_{F}=m \cdot k$ 
Table 1 Roughness values of the workpiece surfaces

\begin{tabular}{|c|c|c|c|c|c|c|c|c|}
\hline \multicolumn{3}{|l|}{ DC06 } & \multicolumn{3}{|l|}{ DP600 } & \multicolumn{3}{|l|}{ AA5182 } \\
\hline $\mathrm{R}_{\mathrm{a}}[\mu \mathrm{m}]$ & $\mathrm{R}_{\mathrm{z}}[\mu \mathrm{m}]$ & $\mathrm{R}_{\mathrm{pk}}[\mu \mathrm{m}]$ & $\mathrm{R}_{\mathrm{a}}[\mu \mathrm{m}]$ & $\mathrm{R}_{\mathrm{z}}[\mu \mathrm{m}]$ & $\mathrm{R}_{\mathrm{pk}}[\mu \mathrm{m}]$ & $\mathrm{R}_{\mathrm{a}}[\mu \mathrm{m}]$ & $\mathrm{R}_{\mathrm{z}}[\mu \mathrm{m}]$ & $\mathrm{R}_{\mathrm{pk}}[\mu \mathrm{m}]$ \\
\hline 1.3532 & 7.2354 & 0.5180 & 1.2970 & 8.4074 & 0.9292 & 0.8820 & 5.7766 & 2.0542 \\
\hline
\end{tabular}

The shear flow stress $\mathrm{k}$ is calculated with the von Mises equivalent stress equation out of the uniaxial tensile flow stress $\sigma_{H S}$ :

$k_{\text {tensile }}=\frac{\sigma_{H S}}{\sqrt{3}}$

The friction force compensation of the testing force $F_{\text {testing }}$ is therefore:

$F_{\text {layer compression }}\left(\varepsilon_{\text {eq }}\right)=F_{\text {testing }}\left(\varepsilon_{\text {eq }}\right)-A \cdot m \cdot \frac{\sigma_{H S}\left(\varepsilon_{e q}\right)}{\sqrt{3}}$

The friction factor $\mathrm{m}$ is determined in the pin extrusion tests as presented above and the flow stress $\sigma_{H S}$ is characterized in uniaxial tensile tests according to DIN EN ISO 6892-1 [34]. Using the power law presented by Hockett and Sherby [35] the flow stress $\sigma_{H S}\left(\varepsilon_{e q}\right)$ is calculated for each strain increment in the layer compression test. For materials with anisotropic hardening, it is expected, that Eq. 8 does not lead to a sufficient friction compensation. Therefore, the shear flow stress $\mathrm{k}$ is additionally calculated with shear test data measured with the test setup from Merklein and Biasutti [36].

$k_{\text {shear }}=\tau_{\text {shear }}$

In this case, the corresponding von Mises equivalent strain is calculated with the von Mises equivalent strain criterion.

$\varepsilon_{\text {eq_shear }}=\frac{\gamma_{\text {shear }}}{\sqrt{3}}$
Both methods use a mean friction factor $\mathrm{m}$. The pressure dependent friction factor is characterized in the pin extrusion test as a mean value. Another simplification in the presented analytical approach is the neglection of the anisotropic material behaviour that lead to an elliptic shape of the stack in layer compression tests. For extremely anisotropic materials like extruded profiles, there could be an inaccuracy due to static friction in the small side of the ellipsoid. For other materials, an almost homogeneous radial distribution of static and dynamic friction can be assumed.

\section{Analytical friction compensation of flow curves}

With the defined formulation of the friction compensation, the true testing force $\mathrm{F}_{\text {layer compression }}$ can be calculated. Thus, pin extrusion tests are performed for all three materials with a PTFE foil as lubricant. After performing three tests for each material, the friction factors, shown in Fig. 5, are determined.

It is apparent that for the two steel grades a similar friction factor of 0.1197 for DC06 and 0.1149 for DP600 occurs. The aluminium shows a reduced friction factor of 0.0896 for the tribological system of polished tool surface PTFE foil and specimen. The lower friction factor of AA5152 suggests that the surface roughness and hardness of the sample, despite of the separation of tool and material surface with the PTFE foil, have an influence on the friction. Due to the lower strength, the roughness peaks in the aluminium alloy will smooth faster, whereby the friction decreases in the experiment. For the flow stress reduction, the measured testing force is reduced

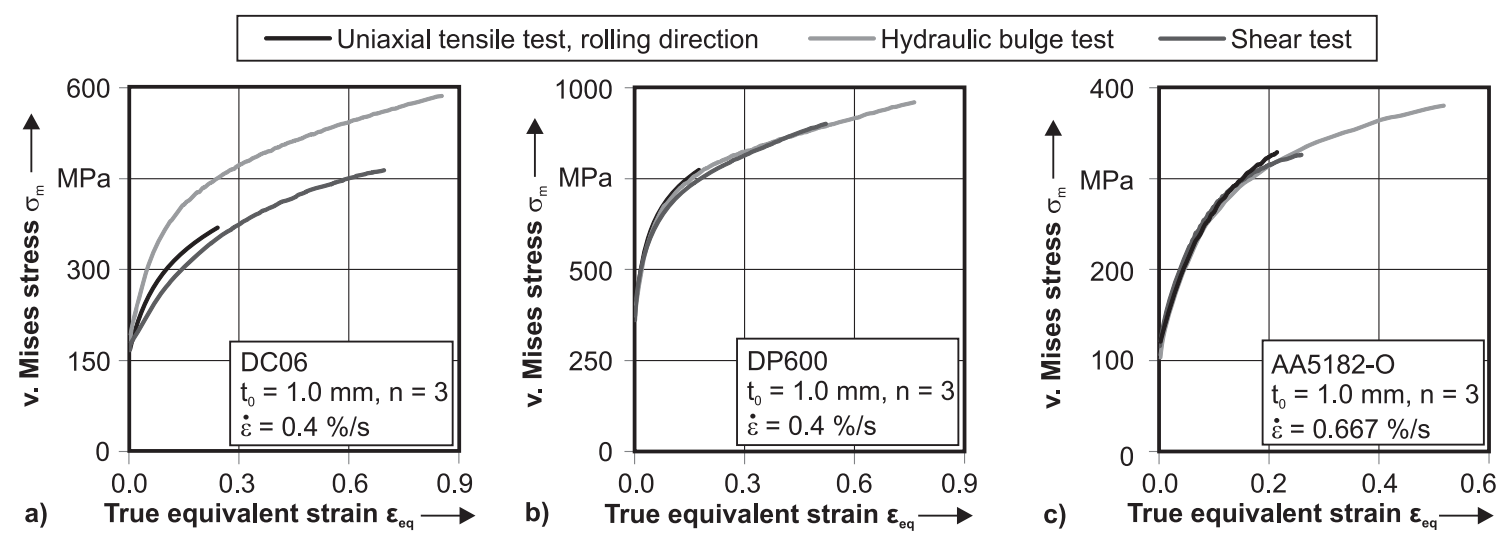

Fig. 3 Flow curves out of uniaxial tensile tests, shear tests and hydraulic bulge tests for a DC06, b DP600 and c AA5182-O 


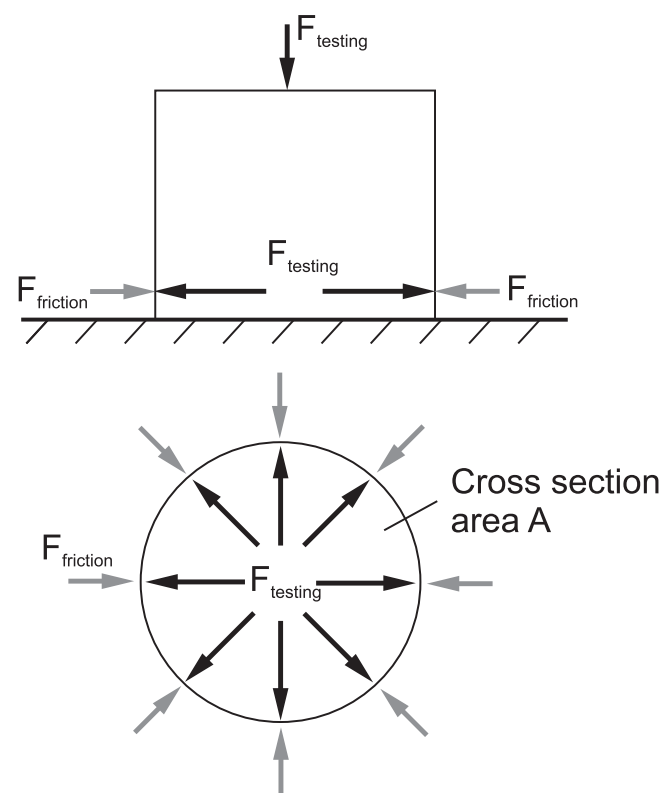

Fig. 4 Schematic depiction of the influence of friction on the testing force

according to eq. 8 . The flow stress calculation is done after eq. 1 for both, the testing force $F_{\text {testing }}$ and the true testing force

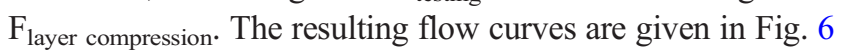
for DC06. For comparison, the flow curve after hydraulic bulging of the same material is also plotted.

For the mild steel, the flow stress measured in layer compression tests is in average 16.1 MPa higher than the flow stress in hydraulic bulge tests, see the bar chart on the right. Due to the calculation over the complete curve, the standard deviation of the stress is very high. With the reduction of the friction, the root mean squared error (RMSE) reduces to 8.2 MPa. This difference is slightly higher than the standard deviation (SD) of the hydraulic bulge test. For this material, the friction compensation overestimates the influence of the friction on the measured force and leads to a flow curve progression below the curve of the hydraulic bulge test. This overestimation of the friction can be relied to the anisotropic material behaviour of the DC06. The stress state dependency

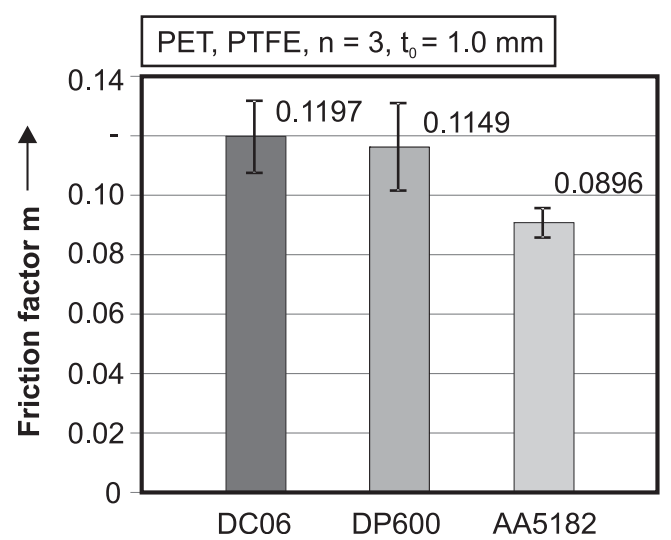

Fig. 5 Friction factors of DC06, DP600 and AA5182 with PTFE foil in pin extrusion tests of the flow stress, yield strength as well as hardening behaviour, is present in this material class [37]. Thus, the simplification of the shear stress calculation with the von Mises equivalent stress criterion, see eq. 7, with uniaxial tensile test data leads to a too high shear stress [38] and therefore to an overestimation of the friction force. With the usage of experimental determined shear stress data based on the test setup [36] the friction force can be recalculated, see Fig. 7.

With the usage of the shear stress, an additional improvement of the friction compensation is possible for the DC06. The resulting deviation between the two flow curves reduces to $4.25 \mathrm{MPa}$ that is within the standard deviation of the hydraulic bulge test. In this case, the usage of additional experimental data leads to a significant improvement of the accuracy in friction mapping.

The results for DP600 are shown in Fig. 8. The dual phase steel has a mean difference of the flow stress between layer compression tests and hydraulic bulge tests of $45.85 \mathrm{MPa}$ over the complete flow curve. With compensation of the influence of the friction with uniaxial tensile test data, the resulting RMSE is reduced to $3.99 \mathrm{MPa}$. This difference of the flow stress is within the standard deviation of the hydraulic bulge test. When using an experimental shear stress curve for the friction force calculation, 4.57 MPa difference is achieved. The flow curves out of layer compression tests end at 0.40 true plastic strain due to the limitations of the maximum force of the testing setup. Considering the standard deviation of both compensation methods, both approaches can be used equally.

The results of the plastic material behaviour for the aluminium alloy are depicted in Fig. 9. For this material, the flow curve of layer compression test without friction force compensation leads to a progression which is $14.08 \mathrm{MPa}$ too high. When reducing the testing force with uniaxial flow stress and the von Mises equivalent stress criterion, the resulting RMSE is about $3.24 \mathrm{MPa}$ that is in very good agreement with the hydraulic bulge test regarding the standard deviation of 3.33 MPa. An additional reduction of the RMSE between layer compression tests and hydraulic bulge tests can be achieved by a friction force calculation with the experimental shear stress curve. The difference between both compensation methods for this material can be explained with the flow curve extrapolation that is necessary for the uniaxial tensile tests. The ultimate elongation is at 0.21 true strain while the layer compression test flow curve has a maximum at 0.42 true strain. Thus, the extrapolation has some uncertainties regarding the prognosed stress at high deformation. For this material, the stress is overestimated which can be seen in the local stress differences that are $1.65 \mathrm{MPa}$ on average regarding the range at the onset of yielding to 0.21 true strain while $4.91 \mathrm{MPa}$ difference on average are observable above 0.21 true strain to the end of the experiment. Shear stress can be measured up to high strains that are above 0.5 true strain, which makes 

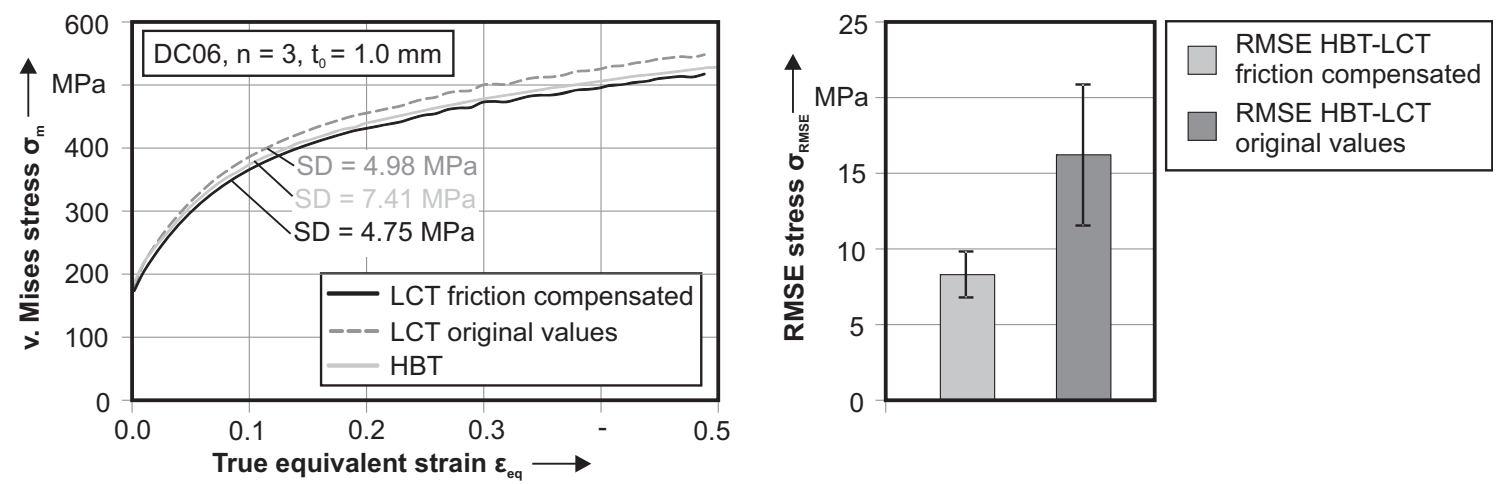

Fig. 6 Biaxial flow curves of DC06 out of hydraulic bulge tests and layer compression tests with and without friction compensation

an extrapolation unnecessary. The influence of a loading direction dependency of the hardening behaviour can be neglected for the AA5182.

With the compensation of the friction influence on the resulting flow curves, a comparison of the resulting yield strength between layer compression test and hydraulic bulge test is done in Fig. 10. The standard deviation is higher in the hydraulic bulge test than in layer compression tests for all three materials. In addition, the resulting yield strength of the layer compression tests with and without the compensation of the friction influence are within the range of the standard deviation of the hydraulic bulge test. Though, the yield strength can be determined with a reduced standard deviation when using the proposed friction compensation.

For all three materials it is apparent that with rising strain an increasing difference of the flow stress between layer compression tests and hydraulic bulge tests exists due to the influence of friction. This explains the high standard deviation of the calculated RMSE of the flow curves. At the onset of yielding, a small difference between hydraulic bulge tests and layer compression tests is visible, while the gap between the flow curves is major at the end of testing due to higher influence of the friction. The increasing difference correlates with the higher testing force due to the two influencing factors of a rising cross section and strain dependency of the friction shear stress. In general, the friction compensation with the proposed friction factor determination in pin extrusion tests leads to significant better results within the standard deviation of the hydraulic bulge test for AA5182 and DP600. The results prove that a determination of the friction factor for each material leads to an adequate compensation of the influence of friction.

For materials with anisotropic hardening behaviour, like DC06, the usage of the von Mises equivalent stress criterion for the shear stress calculation leads to an overestimation of the calculated friction force. For this material, the experimentally measured shear stress is below the calculated shear stress with the von Mises criterion and the usage of uniaxial tensile test data. Thus, the usage of shear tests instead of uniaxial tensile tests has to be considered for an accurate friction force compensation. For materials with a low ultimate elongation, like AA5182, the usage of experimental shear data leads to better results due to the uncertainty in the flow curve extrapolation that leads to an overestimation of the hardening progression in this investigation.

Based on these findings, a compensation of the friction in layer compression tests is possible and leads to an accurate flow behaviour as validated with hydraulic bulge tests. Although, the flow curves of hydraulic bulge test and layer compression test are close to each other at the onset of yielding, the lack of a robust evaluation of the onset of yielding of 0.002 true strain in the hydraulic bulge test emphasizes the necessity of a testing method under low plastic strain that give valid stress values with an acceptable standard deviation.
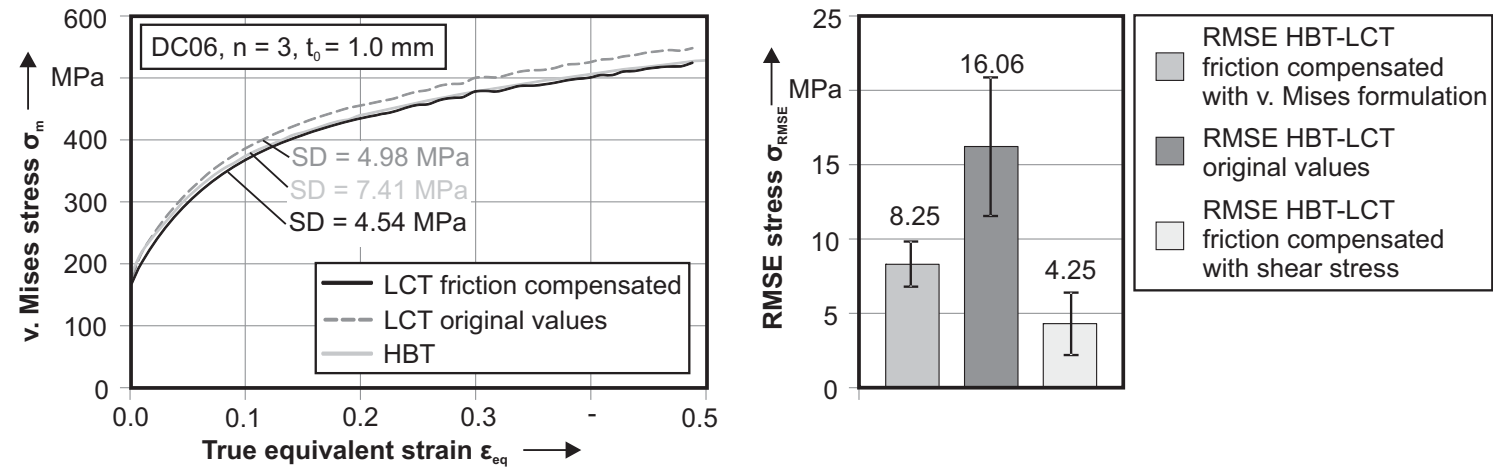

Fig. 7 Biaxial flow curves of DC06 out of hydraulic bulge tests and layer compression tests with and without friction compensation with shear stress data 

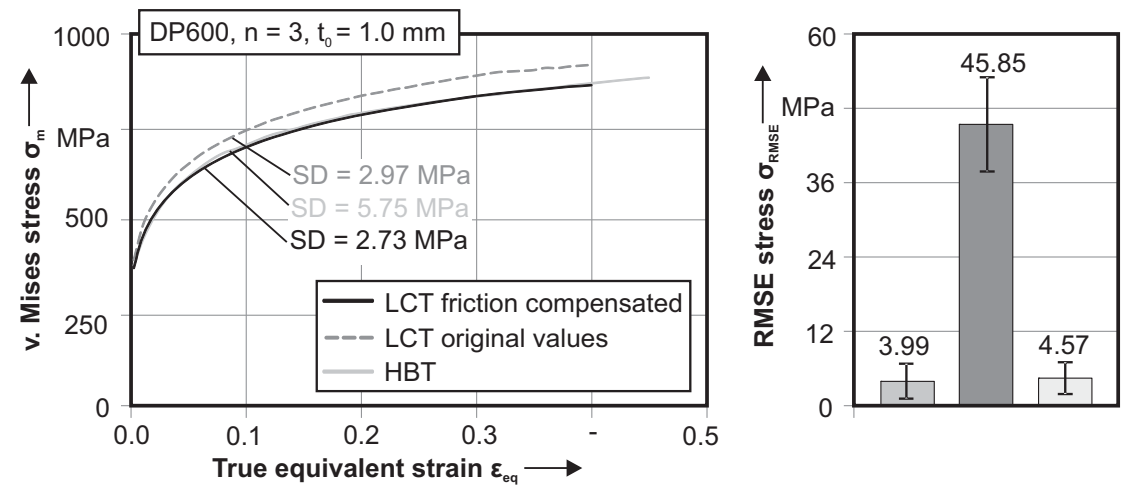

RMSE HBT-LCT

friction compensated

with $\mathrm{v}$. Mises formulation

RMSE HBT-LCT

original values

RMSE HBT-LCT

friction compensated

with shear stress

Fig. 8 Biaxial flow curves of DP600 measured in hydraulic bulge tests and layer compression tests with and without friction compensation using experimental shear data

Necessary for the determination of the friction influence is the characterization of the friction factor of the tribological system. In this investigation, pin extrusion tests are used for the characterization of the mean friction factor and further for the calculation of the portion of friction in the testing force. With this approach, the identification of biaxial flow curves is possible with the layer compression test. Further studies should investigate the influence on the friction force when using a pressure dependent friction characterization method for the compensation.

\section{Alternative friction factor determination}

With the measured data from hydraulic bulge tests and layer compression tests, a calculation of the time dependent friction factor $\mathrm{m}$ can be done and used as validation of the proposed friction force compensation. Thus, the difference of the strain dependent stress between hydraulic bulge tests and layer compression tests can be seen as additional stress due to the friction. The evaluation of the layer compression test is done without any friction compensation. In this case, the testing force is directly used for the calculation of the flow stress:

$\tau_{f}=\Delta \sigma=\sigma_{\text {layer compression }}-\sigma_{\text {hydraulic bulge test }}$
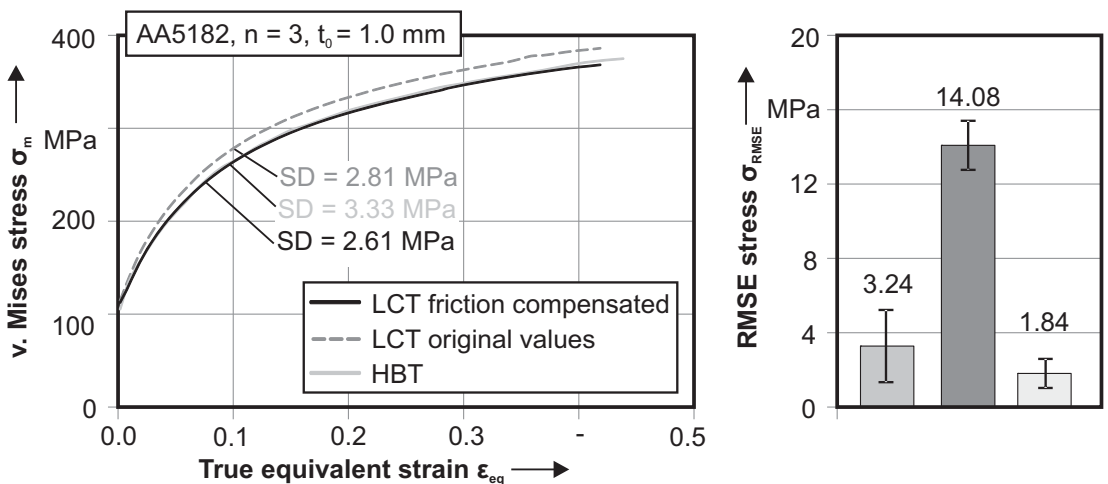

For a common basis, linear interpolation of the flow curves of hydraulic bulge tests and layer compression tests as well as uniaxial tensile test data is done in increments of 0.01 plastic strain. In addition, the influence of the calculation basis of the current shear flow stress $\mathrm{k}\left(\varepsilon_{e q}\right)$ is investigated by using experimental uniaxial and shear stress data. The resulting progression of the friction factor $\mathrm{m}$ for the DC06 is shown in Fig. 11. At the onset of yielding, a transient zone is visible, that ends at 0.07 true strain. Afterwards, an oscillating constant progression with no global increase of the friction factor can be observed. In general, the progression of the friction factor calculated with the experimental shear stress is about 0.004 higher than the curve calculated with tensile test data. This translation of the curve is explained with the different hardening of the DC06 under uniaxial and shear loading [37]. Due to the oscillating curves the standard deviations of both friction factors are comparatively high. The mean friction factor for shear data is $\mathrm{m}=0.0818$, the friction factor for the tensile test data is $\mathrm{m}=$ 0.0772 .

Fig. 9 Biaxial flow curves of AA5182 characterized in hydraulic bulge tests and layer compression tests with and without friction compensation using experimental shear data 


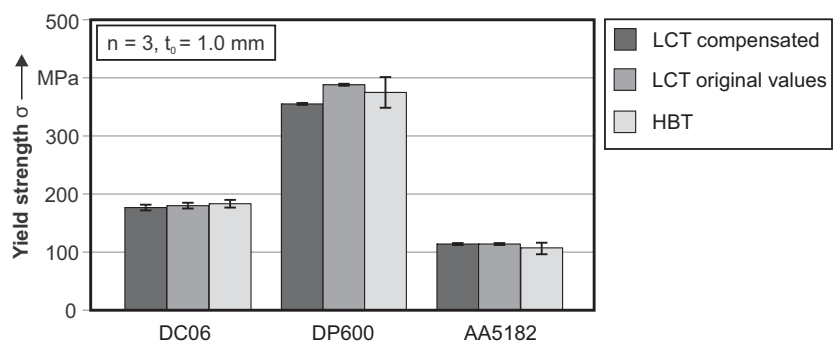

Fig. 10 Yield strength of the materials DC06, DP600 and A5182 characterized in hydraulic bulge test and layer compression test with and without friction compensation

The calculation of the friction factor for the dual phase steel DP600 is given in Fig. 12. At the onset of yielding, a global maximum of the calculated friction factor occurs. From 0.1 on, a homogenous friction factor is visible with a local maximum at 0.32 true strain. The resulting mean friction factor is $\mathrm{m}=0.1017$ for the friction factor calculation with uniaxial tensile test data and $m=0.1036$ when using a shear stress shear strain curve. The increasing difference between both curves can be explained with the flow curve extrapolation under uniaxial tension that leads to a slightly wrong hardening progression of the material.

For the aluminium, there is unsteadiness at the beginning of plastic deformation, see Fig. 13. With rising plastic deformation, a continuous downward trend is observable that leads to a mean $\mathrm{m}$ value of $\mathrm{m}=0.0812$ with a standard deviation of 0.0113 when using shear data for the calculation. This downward trend can be explained with the lower hardness of the aluminium that leads to a flattening of the roughness peaks of the specimen and reduces the friction over the test. A similar progression can be observed when evaluation the friction factors with uniaxial tensile test data. In this case the downward trend is more pronounced and results in a friction factor of $\mathrm{m}=0.0775$. The roughness measurement of the specimen after testing proves the flattening of the roughness peaks, see Table 2. The reduced peak height $R_{p k}$ changes significant during testing, while the mean roughness $\mathrm{R}_{\mathrm{a}}$ stays constant.

For all three materials it is apparent that in the beginning of the plastic deformation, there is a discontinuity in the friction

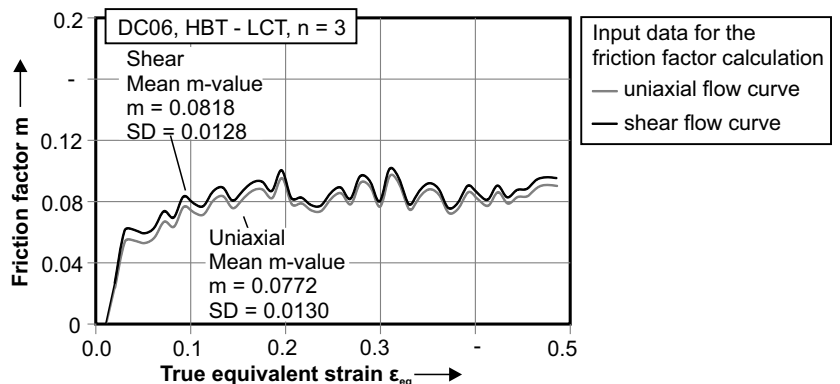

Fig. 11 Resulting strain dependent friction factor of DC06 by using shear and uniaxial tensile test data

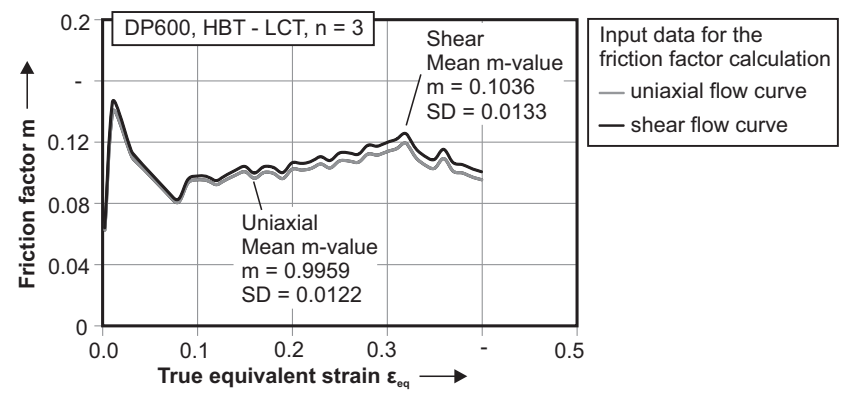

Fig. 12 Friction factor of DP600 according to the true plastic strain

factor progression until 0.05 true plastic strain. This can be relied with two major influencing factors. At first, there is a transient zone between static friction and sliding friction. Second, there is the inaccuracy in the stress evaluation in hydraulic bulge tests that can lead to false results until 0.05 true plastic strain [8]. It has to be proven whether the friction factor model is applicable at the onset of yielding or the friction coefficient model would lead to better results there. A second aspect that is neglected is the pressure dependency of the friction factor which is not mapped in pin extrusion test. A third aspect is the flattening of the specimen surface that lead to a reduction of the friction factor as seen for the aluminium alloy. This influence is also neglected in the pin extrusion test. For this investigation, the pin extrusion test was performed to $50 \%$ compression of the sheet metal specimen. Thus, all results depict a mean value in this strain range. An improvement would be a strain and pressure dependent characterization method for the friction factor.

When calculating the mean friction factors, as shown in Fig. 14, a good conformity between the friction factor derived from pin extrusion test and the friction factor calculated out of the difference between hydraulic bulge tests and layer compression tests is present for DP600 and AA5182. There, the experimental determined friction factors are within the standard deviation comparable to the pin extrusion test results. A slight increase of the friction factors is visible, when using the experimental shear stress data instead of the uniaxial tensile test data. For the DC06 there is a higher deviation. One reason for the resulting gap can be found in the friction factor calculation in the pin

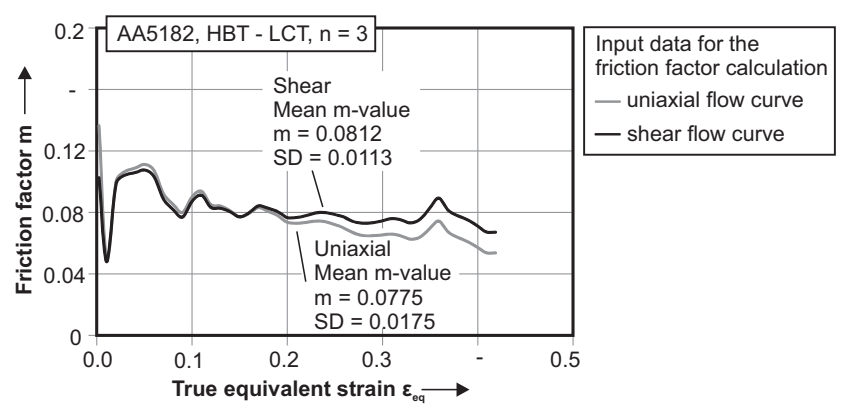

Fig. 13 Strain dependant friction factor of AA5182 
Table 2 Roughness values of AA5182 before and after testing

\begin{tabular}{|c|c|c|c|c|c|c|}
\hline \multirow[t]{2}{*}{ AA5182 } & \multicolumn{3}{|c|}{ Before testing } & \multicolumn{3}{|c|}{ After testing } \\
\hline & $\mathrm{R}_{\mathrm{a}}[\mu \mathrm{m}]$ & $\mathrm{R}_{\mathrm{pk}}[\mu \mathrm{m}]$ & $\mathrm{R}_{\mathrm{z}}[\mu \mathrm{m}]$ & $\mathrm{R}_{\mathrm{a}}[\mu \mathrm{m}]$ & $\mathrm{R}_{\mathrm{pk}}[\mu \mathrm{m}]$ & $\mathrm{R}_{\mathrm{z}}[\mu \mathrm{m}]$ \\
\hline & 0,882 & 20,542 & 57,766 & 0,903 & 1002 & 5581 \\
\hline SD & 0,061 & 0,180 & 0,178 & 0,039 & 0,223 & 0,394 \\
\hline
\end{tabular}

extrusion test. The numerical identification uses the uniaxial tensile test data for the hardening progression of the material that leads to a wrong influence of the friction in the numerical approach. An improvement could be achieved when using a 3D numerical model and a more complex material model that can map the anisotropic hardening of the DC06. For this material, the shear strain calculation with the von Mises equivalent strain criterion leads to a wrong classification of the shear stress values to the strain in layer compression tests. Thereby, the anisotropic hardening is not mapped adequate. If there is no shear test data available, a more complex equivalent stress criterion, for example Yld2000-2d, could be used to calculate the shear stress more accurate. In general, the friction factor calculation with experimental determined shear flow stress leads to a slightly more accurate result when comparing the results with pin extrusion test.

Due to the comparability of the two friction factor identification methods, in the case of sheet bulk metal forming, the hydraulic bulge test and the layer compression test are an alternative for the friction factor calculation. The advantage here is the experimental setup without any need of validated numerical simulation of the process or assumptions to the barrelling in compression tests. Another advantage is the need for one of the two testing setups for the material model identification beside of the uniaxial tensile test data that is needed anyway as input for the hardening behaviour. Future work has to clarify that the proposed methodology can be used for the friction factor determination for different friction conditions like dry forming or at forming operations with different lubricants. In general the calculated friction factor with shear stress data leads to better results because of two major aspects. On the one side, the anisotropic hardening cannot

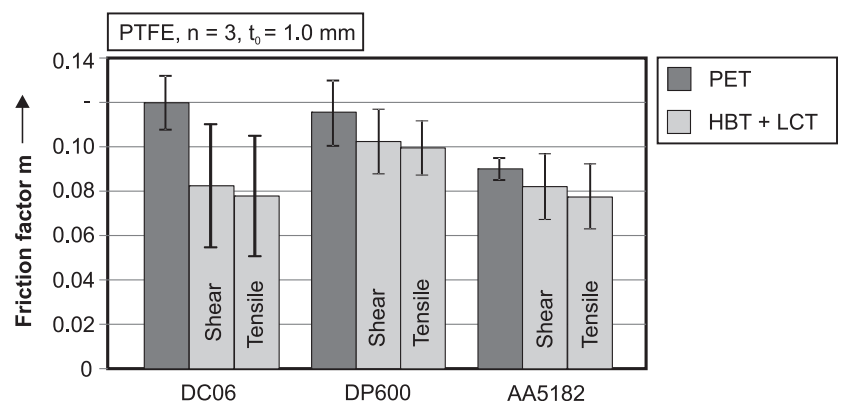

Fig. 14 Comparison of calculated friction factors in pin extrusion tests and biaxial tests be considered with uniaxial flow curves. On the other side, the extrapolation of tensile test data can lead to a wrong hardening prognosis and thus to a rising difference between real and extrapolated material behaviour.

The calculation of friction factors when comparing the two resulting flow curves out of layer compression tests (with friction) and hydraulic bulge tests (without friction) is possible and leads to comparable friction factors as in pin extrusion tests. This approach gives the opportunity to analytically calculate friction factors without the need of any numerical model for the inverse determination of the friction factor as necessary in the pin extrusion test. For this calculation, two major influencing factors have been determined. On the one hand, the loading path dependent hardening of the DC06 leads to a translation of the calculated friction factor progression to a more accurate value when using experimental shear data and not data calculated with an equivalent stress criterion. On the other hand, the hardening extrapolation has significant influence on the calculated friction factor progression. Especially for materials with low ultimate elongation, a wrong hardening prognosis leads to a wrong progression of the friction factor in the strain area above the ultimate elongation as seen for the AA5182 and DP600.

\section{Discussion}

Experimental data from pin extrusion tests of the materials DC06, DP600 and AA5182 with PTFE foil as lubricant is used to recalculate the resulting flow curves of layer compression tests with respect to the friction condition. Due to the high contact pressure between tool and workpiece, the friction factor model is used to determine the friction. For all investigated materials, the friction factor is numerically identified and is further used for the friction force reduction of the measured testing force. Results of the pin extrusion test reveal an influence of the sheet material that is used. A generalized test for the friction system of tool and PTFE foil is not suitable. Especially between steel and aluminium alloys, a significant difference of the resulting friction factor is measurable. The friction factors for steel are about 0.025 higher than the $\mathrm{m}$ value of the AA5182 that is 0.0896 . With the determined friction conditions, the flow curves of layer compression tests are recalculated, which leads to a significant reduction of the resulting flow curve. It is clearly visible that the influence of the friction rises with increasing plastic strain for all materials due to the increasing cross section of the specimen and the strain dependency of the friction force formulation. Although the friction has no major impact on the flow stress in layer compression tests, the usage of hydraulic bulge tests for the material modelling at 0.002 plastic strain is limited due to the high standard deviation under 0.05 plastic strain. 
For verification of the proposed friction force compensation method, hydraulic bulge tests are used to determine friction free flow curves of the same three materials. The comparison of the flow curves shows a very good comparability with a root mean squared error lower than the standard deviations of the tests itself for the dual phase steel and the aluminium. The mild steel reveals a comparatively high deviation of $8.2 \mathrm{MPa}$ between layer compression tests and hydraulic bulge tests that is relied to the anisotropic hardening behaviour of this material class. The friction force calculation instead is based on the von Mises equivalent stress formulation that uses uniaxial tensile test data. With the knowledge of the real flow behaviour under shear load, the resulting root mean squared error can be halved for the DC06. When using shear material data in the numerical identification of the friction factor, another improvement of the accuracy is expected. Another advantage of the experimental shear stress is the high reachable strain under this loading condition that makes an extrapolation of uniaxial flow stress obsolete and lead to a better friction force compensation and $\mathrm{m}$-value calculation in the case of AA5182 and DP600. It is mentionable that the calculated friction factor is very sensitive to the used current shear flow stress $\mathrm{k}$ but is not that sensitive to the friction force compensation. This leads to the conclusion, that a moderate standard deviation of 0.01 in the friction factor determination will not affect the friction force compensation in a major way.

Using test data only from hydraulic bulge tests and layer compression tests, an alternative friction factor calculation is possible. The resulting friction factors are in good conformity to the results of pin extrusion tests for the DP600 and the AA5182. For the DC06, a difference between the friction factors is visible due to the above mentioned anisotropic hardening that is not taken into account in the pin extrusion test. For all materials, an unequally progression at the onset of yielding is visible. This is relied to the inaccurate evaluation of flow curves in hydraulic bulge tests below 0.05 true strain and to the transient zone between static and sliding friction at the onset of yielding, that cannot be mapped with the friction factor model. Thus, in the case of sheet material, a new method for friction factor determination is available. Advantage in the proposed methodology is the neglect of assumptions to curvature as in the barrel compression tests or the inverse parameter identification in pin extrusion tests. Most of the necessary tests have to be done anyway for the material characterization of the material model. Uniaxial tensile tests are used for the description of the material hardening and the yield locus. Layer compression tests or hydraulic bulge tests are needed for the yield locus as well. One of both tests has to be done additionally instead of another test for the friction determination. Thus the amount of testing procedures stays equal, while the friction factor determination becomes more easy.

\section{Conclusion and outlook}

The provision of defined material parameters for the numerical design of forming operations increases to the same degree as the complexity of the mathematical models used in the simulation software. Many material models use the equibiaxial yield point for the parameter identification. Several setups for equi-biaxial testing can be found in literature. The most common are the layer compression test and the hydraulic bulge test. Due to the absence of friction, the hydraulic bulge test is a very accurate test for the flow curve characterization, but is not very accurate at the onset of yielding. The layer compression test is precise also at the beginning of plastic deformation but is subjected to friction due to the contact between the tool and workpiece. Thus, a friction compensation method is proposed in this contribution. Quintessence of this contribution is:

- Friction influences the flow behaviour characterized in layer compression tests. For friction compensation, the friction factor is characterized in pin extrusion tests and used for the recalculation of the flow stress. Results are in good accordance to hydraulic bulge tests. This test can be seen as friction free and represents a similar stress state.

- For the friction compensation a critical shear stress is needed. When using an equivalent stress strain criterion and uniaxial tensile test flow curves, materials with anisotropic hardening will show an incorrect determination of the friction shear stress because of the differing material hardening. Flow curve extrapolation will also affect the accuracy of the friction force calculation since the hardening behaviour is not mapped accurate in every case. By using shear flow curves the friction shear stress can be calculated more accurate for materials with anisotropic hardening.

- The tribological system containing a PTFE foil as lubricant has no general friction factor for PTFE, as the sheet material influences significant the determined friction factors. Especially the aluminium AA5182 which has a stronger flattening of the roughness peaks shows a lower friction factor.

- By compensating the friction influence in flow curves of layer compression tests, the onset of yielding in the equibiaxial stress state can now be determined with sufficient accuracy.

- With hydraulic bulge tests and layer compression tests, an alternative methodology can be used to determine the friction factor for sheet materials by defining a stress difference in each strain increment and using shear test data for the analytical calculation of friction factors. This gives the opportunity for a direct friction factor calculation without any need of numerical parameter identification as necessary in pin extrusion tests. 
Regarding the anisotropic material behaviour of mild steel, a more complex equivalent strain criterion should lead to a more accurate shear stress calculation with uniaxial tensile test data. Especially the anisotropic hardening of this material class has to be considered. Further investigation for aluminium should focus the flattening during the deformation that led to a reduction of the calculated friction with rising deformation. Due to the anisotropic material behaviour, the friction compensation could be further improved by considering the plastic anisotropy in the analytical model. Since the difference in the flow stress in rolling and transversal direction will lead to a more accurate friction compensation especially for strongly anisotropic materials.

Acknowledgements The authors would like to thank the German Research Foundation (DFG) for supporting the present investigations which were performed within the scope of the research project "Improvement of the mapping accuracy in the material modeling by considering the yield locus under plane strain (DFG ME 2043/77-1)".

Funding Information Open Access funding provided by Projekt DEAL.

\section{Compliance with ethical standards}

Conflict of interest The authors declare that they have no conflict of interest.

Open Access This article is licensed under a Creative Commons Attribution 4.0 International License, which permits use, sharing, adaptation, distribution and reproduction in any medium or format, as long as you give appropriate credit to the original author(s) and the source, provide a link to the Creative Commons licence, and indicate if changes were made. The images or other third party material in this article are included in the article's Creative Commons licence, unless indicated otherwise in a credit line to the material. If material is not included in the article's Creative Commons licence and your intended use is not permitted by statutory regulation or exceeds the permitted use, you will need to obtain permission directly from the copyright holder. To view a copy of this licence, visit http://creativecommons.org/licenses/by/4.0/.

\section{References}

1. Hill R (1990) Constitutive modelling of orthotropic plasticity in sheet metals. J Mech Phys Solids 38(3):405-417

2. Barlat F, Lege DJ, Brehm JC (1991) A six-component yield function for anisotropic materials. Int J Plast 7(7):693-712

3. Barlat F, Brem JC, Joon JW, Chung K, Dick RE, Lege DJ, Porboghrat F, Choi SH, Chu E (2003) Plane stress yield function for aluminum alloy sheets - part 1: theory. Int J Plast:1297-1319

4. Banabic D, Balan T, Comsa D (2000) "A new yield criterion for orthotropic sheet metals under plane-stress conditions," The 7th Conf. "TPR2000" Cluj Napoca, pp. 217-224

5. ISO/DIS 16808:2014-11: Metallic materials - Sheet and strip Determination of biaxial stress-strain curve by means of bulge test with optical measuring system. Deutsches Institut für Normung e.V., Berlin: Beuth, 2014.

6. N.N., ISO 16842 (2014-10-00):Metallic materials - Sheet and strip - Biaxial tensile testing method using a cruciform test piece, 2014.
7. Güner A, Brosius A, Tekkaya AE 2009 "Analysis of the hydraulic bulge test with FEA concerning the accuracy of the determined flow curves," Key Eng Mater, pp. 439-447

8. Panknin W (1959) Der hydraulische Tiefungsversuch und die Ermittlung von Fließkurven. Dissertation Technische Hochschule Stuttgart, Stuttgart

9. An YG, Vegter H (1998) "The difference in plastic behaviour between the bulging test and the through-thickness compression test for sheet steels and Al alloys," Proceedings IDDRG Working Group Meeting 1998, pp. 1-5

10. Vegter H, An Y (2008) "Mechanical testing for modeling of the material behaviour in forming simulations," Proceedings of the Numisheet Conference 2008, pp. 55-60

11. An Y, Vegter H (2005) Analytical and experimental study of frictional behavior in through-thickness compression test. J Mater Process Technol 160:148-155

12. An Y, Vegter H (1999) "Experimental study of the friction behavior in the compression test," Proceedings of the IDDRG Conference 1999, pp. 1-6

13. Eder M, Gaber C, Nester W, Hoffmann H, Volk W (2018) Innovative measurement technique to determine equibiaxial curves of sheet metals using a modified Nakajima test. CIRP Ann Manuf Technol 67:265-268

14. Hochholdinger B, Grass H, Lipp A, Hora P (2009) "Determination of Flow Curves by Stack Compression Tests and Inverse Analysis for the Simulation of Hot Forming," Proceedings 7th European LSDYNA Conference, pp. 1-11

15. Alves LM, Nielsen CV, Martins P (2011) Revisiting the fundamentals and capabilities of the stack compression test. Exp Mech 51: $1565-1572$

16. Shaw MC, Ber A, Mamin PA (1960) Friction Characteristics of Sliding Surfaces Undergoing Subsurface Plastic Flow. J Basic Eng 82:342-346

17. Ebrahimi R, Najafizadeh A (2004) A new method for evaluation of friction in bulk metal forming. J Mater Process Technol 152:136143

18. Schrader T, Shirgaokar M, Altan T (2007) A critical evaluation of the double cup extrusion test for selection of cold forging lubricants. J Mater Process Technol:36-44

19. Vierzigmann U (2016) Beitrag zur Untersuchung der tribologischen Bedingungen in der Blechmassivumformung - Bereitstellung von tribologischen Modellversuchen und Realisierung von Tailored Surfaces, vol. 288, Meisenbach GmbH Verlag

20. Male AT, Cockroft MG (1964) A Method for the Determination of the Coefficient of Friction of MEtals under Conditions of Bulk Plastic Deformation. J Inst Met 93:38-46

21. Hörlacher U (1989) Prüfung von Schmierstoffadditiven auf das Tribosystem bei der Kaltmassivumformung, vol. 104, B. A. D. I. f. Umformtechnik, Ed., Berlin: Springer

22. Rajesh E, SivaPrakash M (2013) Analysis of friction factor by employing the ring compression test under different lubricants. Int J Sci Eng 4(5):1163-1171

23. Sofuoglu H, Gedikli H (2002) Determination of friction coefficient encountered in large deformation processes. Tribol Int 35:27-34

24. N.N., "DIN 50106 - Prüfung metallischer Werkstoffe Druckversuch bei Raumtemperatur DIN 50106:2016-11,” Beuth, Berlin, 2016.

25. Merklein M, Kuppert A (2009) A method for the layer compression test considering the anisotropic material behavior. Int J Mater Form $2: 483-483$

26. Hesse B, Sonne HM, Rohiller G (1991) Zuverlässige Dehngrenzen im rechnergesteuerten. Materialprüfung:208-211

27. Suttner S, Merklein M (2016) Experimental and numerical investigation of a strain rate controlled hydraulic bulge test of sheet metal. J Mater Process Technol:121-133 
28. Min J, Stoughton TB, Carsley JE, Carlson BE, Lin J, Gao X (2017) Accurate characterization of biaxial stress-strain response of sheet metal from bulge testing. Int J Plast:192-213

29. Burgdorf M (1966) Untersuchungen über das Stauchen und Zapfenpressen, vol. 5, B. A. D. I. f. Umformtechnik, Ed., Essen: Girardet

30. DIN 8582: Manufacturing processes forming Classification, subdivision, terms and definitions, alphabetical index, Berlin: Beuth Verlag $\mathrm{GmbH}, 2003$.

31. Kraus M, Andreas K, Stellin T, Engel U, Merklein M (1896) Modification of Tribological Conditions for Influencing the Material Flow in Bulk Forming of Microparts from Sheet Metal. AIP Conf Proc 1:2017

32. Picu R, Vincze G, Ozturk F, Garcio J, Barlat F, Maniatty A (2005) Strain rate sensitivity of the commercial aluminum alloy AA5182O. Mater Sci Eng A 390:334-343

33. DIN EN ISO 4287: Geometrische Produktspezifikation (GPS) Oberflächenbeschaffenheit: Tastschnittverfahren - Benennungen, Definitionen und Kenngrößen der Oberflächenbeschaffenheit, Berlin: Beuth Verlag GmbH, 2010.
34. DIN EN ISO 6892-1:2014: Metallische Werkstoffe - Zugversuch Teil 1: Prüfverfahren bei Raumtemperatur (ISO/DIS 6892-1: 2014); Deutsche Fassung prEN ISO 6892-1:2014. Deutsches Institut für Normung e.V., Berlin: Beuth, 2014.

35. Hockett JE, Sherby OD (1975) Large strain deformation of polycrystalline metals at low homhlogous temperatures. J Mech Phys Solids 23:87-98

36. Merklein M, Biasutti M (2011) Forward and Reverse Simple Shear Test Experiments for Material Modelling in Forming Simulations. Steel Res Int:702-707

37. Dorn JE (1949) Stress-Strain Rate Relations for Anisotropic Plastic Flow. J Appl Phys 20:15-20

38. Lenzen M, Affronti E, Rosenschon M, Merklein M (2016) Investigation of the anisotropic strain rate dependency of AA5182-O and DC04 for different stress states. Adv Mater Res 1140:35-42

Publisher's note Springer Nature remains neutral with regard to jurisdictional claims in published maps and institutional affiliations. 